\title{
Design of Design: Empowering K-12 Educators to Develop Unique Standards- aligned Engineering Design Exercises in Their Own Classrooms
}

\section{Dr. Amy Trauth, University of Delaware}

Amy Trauth, Ph.D., is the Senior Associate Director of Science Education at the University of Delaware's Professional Development Center for Educators. In her role, Amy works collaboratively with K-12 science and engineering teachers to develop and implement standards-based curricula and assessments. She also provides mentoring and coaching and co-teaching support to K-12 teachers across the entire trajectory of the profession. Her research focuses on teacher education, classroom assessment, and P-16 environmental and engineering education.

\section{Prof. Jenni Buckley, University of Delaware}

Dr. Buckley is an Associate Professor of Mechanical Engineering at University of Delaware. She received her Bachelor's of Engineering (2001) in Mechanical Engineering from the University of Delaware, and her MS (2004) and PhD (2006) in Mechanical Engineering from the University of California, Berkeley, where she worked on computational and experimental methods in spinal biomechanics. Since 2006, her research efforts have focused on the development and mechanical evaluation of medical and rehabilitation devices, particularly orthopaedic, neurosurgical, and pediatric devices. She teaches courses in design, biomechanics, and mechanics at University of Delaware and is heavily involved in K12 engineering education efforts at the local, state, and national levels.

\section{Dr. Debra J. Coffey, University of Delaware}


DESIGN OF DESIGN: EMPOWERING K12 EDUCATORS TO DEVELOP UNIQUE STANDARDS-ALIGNED ENGINEERING DESIGN EXERCISES IN THEIR OWN CLASSROOMS (RTP)

\author{
Amy E. Trauth, $\mathrm{PhD}^{1}$; Deborah Coffey, $\mathrm{PhD}^{1}$; Chrystalla Mouza, EdD ${ }^{1}$; \\ Jenni M. Buckley, $\mathrm{PhD}^{2}$ \\ ${ }^{1}$ University of Delaware, College of Education and Human Development \\ ${ }^{2}$ University of Delaware, College of Engineering
}




\section{Introduction}

With the publication of the Framework for K-12 Science Education (National Research Council, 2012) and the Next Generation Science Standards (NGSS), emphasis is now placed on the integration of engineering principles and practices into K12 science education. Although only 18 states and the District of Columbia have formally adopted the NGSS, other states, including South Dakota, Montana, Pennsylvania, and West Virginia have adopted similar standards. Unlike the previous set of national science education standards (NRC, 1996), the Framework for K-12 Science Education (NRC, 2012) places engineering and technology alongside the natural sciences for two critical reasons: to reflect the importance of understanding the human-built world and to recognize the value of better integrating the teaching and learning of STEM fields. It is assumed that students who have learned disciplinary core ideas, practices, and crosscutting concepts of science and engineering will be scientifically literate citizens who can engage in public discussions on related issues and can be careful consumers of scientific and technological information, and can pursue careers of their choice, including STEM careers. Engineering design allows teachers to effectively blend disciplines and integrate math and science as a means of building student understanding of and skills for engaging in both content areas and appreciation for both content areas (Lehman \& Capobianco, 2012).

Pre-college engineering education providers, such as Project Lead The Way (PLTW) and Engineering Is Elementary (EiE), offer comprehensive curricula and professional learning opportunities in engineering education. These programs are high quality and provide an entry point into engineering education for K12 teachers with turnkey curricula; the engineering design lessons and activities are prescriptive and vary in the degree to which they explicitly address the science concepts and skills inherent to the design problem. Moreover, PLTW and EiE are not explicitly designed to address the performance expectations of NGSS. These performance expectations are intended to be the benchmark by which students' proficiency of the gradeappropriate disciplinary core ideas, practices, and crosscutting concepts are assessed. It is unlikely that extant engineering curricula will meet the requirements of including engineering in regular K-12 science instruction set forth by the NRC's Framework.

\section{Purpose and research questions}

Teachers are the cornerstone of any effort to change K-12 education. Thus, the inclusion of engineering concepts and principles in the NRC's Framework indicates a concomitant need to provide inservice teachers with professional learning on how and when to integrate engineering educational experiences for students. Teaching science and engineering as envisioned by NRC's Framework requires teachers to have strong foundational knowledge of content knowledge and practices of the two domains. Until now, preservice and inservice teacher education has rarely addressed the foundational principles of engineering design, the skills for developing and implementing engineering design curricula, and the pedagogical skills for supporting high quality engineering education in classrooms (Lehman \& Capobianco, 2012; Reimers et al., 2015). Our project attempts to address this gap by studying the efficacy of a three-year effort to develop and implement professional learning focused on engineering design for K12 teachers. The goal of our project was to increase K12 teachers' knowledge of engineering design, their skills for creating and adapting engineering curricula, and their confidence and skills for implementing engineering curricula in their classrooms. Our study was guided by the following research questions: 
(1) To what extent did K12 teachers' knowledge of engineering design change during their participation in professional learning?

(2) To what extent were teachers able to create and/or adapt engineering design problems aligned with the Next Generation Science Standards and Common Core State Standards for Mathematics?

(3) To what extent were teachers' confidence and skills for enacting engineering design in their classrooms influenced by their participation in professional learning?

\section{Literature review}

Teachers' knowledge and skills for engineering. Although many research-based principles regarding the formulation and implementation of curriculum and assessment can be applied to engineering education, the nature of engineering design is distinct from other STEM domains. As such, teacher must be able to support and evaluate students' learning from engineering design problems, in part, by determining the quality of students' solutions (Brophy, Klein, Portsmore, and Rogers, 2008). Prior research illustrates the wide range of content knowledge and pedagogical skills for engineering design among K12 teachers. Hsu, Purzer, and Cardella (2011) showed that many teachers do not feel prepared to teach engineering design despite acknowledging its importance in K12 education. As a result, K12 teachers need professional learning experiences with grade-band appropriate content knowledge alongside engineering design processes. Professional learning experiences should make explicit the process creating or adapting curricula for classroom-based engineering design for students.

Engineering design tasks that integrate math and science concepts are effective for increasing teachers' content knowledge (Pinnell, Rowley, Preiss, Blust, Beach, and Franco, 2013; Zarske, Sullivan, Carlson, and Yowell, 2004) as well as actively engaging teachers in recognizing the processes inherent to engineering design (Duncan, Diefes-Dux, and Gentry, 2011). Despite these findings, even when teachers participate in professional learning, they can still hold naïve conceptions about the engineering design process. For instance, a study by Hynes (2012) indicated that middle grades teachers conflated miniature representations of objects and tools with testable prototypes that are intended to function as designed (Dym and Little, 2004). Moreover, teachers were unclear about the difference between multiple iterations of designs versus multiple versions of an object that is improved over time. This finding points to the need for sustained support in learning to teach engineering design. Guzey, Tank, Wang, Roehrig, and Moore (2014) showed that nearly half of teacher were able to formulate complete engineering design lessons that were relevant for students and included opportunities for redesign based on weaknesses of the original design. Collectively, these findings indicate the need for relevant, sustain professional learning for K12 teachers who are expected to implement engineering design as a part of regular classroom instruction.

Professional learning for teachers of engineering. To grow teachers' knowledge and skills for engineering design, effective professional learning for teachers of engineering involves active engagement of participants in authentic and exploratory design challenges rather than simply learning about the newest pre-packaged curriculum (Reimer et al., 2015). In fact, Daugherty and Custer (2012) indicated that professional learning on established curricula often overemphasizes engaging teachers in the curriculum's instructional activities so as to ensure fidelity of implementation. The tradeoff of this type of professional learning model is that 
teachers are unlikely to expand their pedagogical content knowledge or develop skills for making critical choices about the sequencing and content of engineering design challenges.

Cunningham and Carlsen (2014) suggested that professional learning on engineering design should incorporate the following activities: engage teachers in engineering practices through design challenges, model pedagogies that support those practices, give teacher experiences as both learners and teachers, support development of teachers' understanding of the interconnectedness between science and engineering, and help teacher understand engineering as a social practice. Effective design challenges in professional learning should engage participants in problem-solving, brainstorming possible solutions, learning how to use tools of engineering comfortably and with precision and how to fairly test early prototypes for adherence to design criteria and constraints (Custer and Daugherty 2009). Moreover, design challenges in professional learning should afford teachers opportunities to use the same communication and collaboration skills as those of engineers - work effectively as part of a team, ask questions about design specifications, cooperatively communicate with team members, and carefully document design iterations and data from testing of prototypes. These types of learning opportunities have been shown effective for increasing teachers' content knowledge of engineering design (Custer and Daugherty, 2009; Donna, 2012; English, Hudson, and Dawes, 2013; Moore et al., 2014).

Supporting teachers' pedagogical content knowledge is also enhanced by active participation in design challenges when those challenges are coupled with deep, guided reflection about the types of pedagogical tools and strategies used by their facilitators and how these tools and strategies would support their students' learning in the context of their own classrooms (Penuel, Fishman, Yamaguchi, and Gallagher, 2007; Rogers, Abell, and Lannin, 2007). This means that facilitators themselves must model highly effective pedagogical practices during professional learning so as to deepen teachers' knowledge of the types of strategies useful for supporting learners' engagement in engineering design (Donna, 2012; Johnson and Saylor, 2014; Reimers et al., 2015).

\section{Methods}

Study context and participants. This study data presents a from a three-year project to develop and implement a professional learning institute for K12 teachers focused on engineering design. This project, funded through a Title II Improving Teacher Quality grant, was executed as a partnership between the colleges of education and engineering at a mid-sized state university. The professional learning institute comprised a weeklong experience in which teachers engaged in three design experiences - the first, challenge to create a prosthetic (working prototype) for a three-legged dog; the second, to "hack" an existing engineering lesson to more closely align it to content standards and produce an exemplar prototype; the third, to brainstorm engineering design problems and topics relevant to students, plan instruction around one chosen engineering problem, and produce an exemplar prototype. The goals and activities of the professional learning institute can be found in Table 1. 
Table 1. Professional learning goals and associated activities.

\begin{tabular}{|c|c|}
\hline Professional Learning Goals & Professional Learning Activities \\
\hline $\begin{array}{l}\text { Develop working } \\
\text { knowledge of engineering } \\
\text { design processes }\end{array}$ & $\begin{array}{l}\text { Used a three-phase design process (see Figure 1) to engage } \\
\text { teachers in three design challenges }\end{array}$ \\
\hline $\begin{array}{l}\text { 2. Differentiate between } \\
\text { engineering design and } \\
\text { making }\end{array}$ & $\begin{array}{l}\text { Reviewed examples of engineering and making, identified } \\
\text { criteria for engineering design to clarify its difference from } \\
\text { making }\end{array}$ \\
\hline $\begin{array}{l}\text { 3. Apply common modeling } \\
\text { and prototyping } \\
\text { techniques }\end{array}$ & $\begin{array}{l}\text { Used standard power tools and technologies (e.g., 3D printer) } \\
\text { to create functional first-generation prototypes for design } \\
\text { challenges }\end{array}$ \\
\hline $\begin{array}{l}\text { 4. Formulate engineering } \\
\text { design problems aligned } \\
\text { to grade level standards }\end{array}$ & $\begin{array}{l}\text { Reviewed NGSS and CCSS math standards, identified } \\
\text { potential synergies between content standards and students' } \\
\text { interests to generate a list of engineering design problems } \\
\text { appropriate for each grade band }\end{array}$ \\
\hline $\begin{array}{l}\text { 5. Develop pedagogical } \\
\text { content knowledge for } \\
\text { implementing engineering } \\
\text { design in classrooms }\end{array}$ & $\begin{array}{l}\text { Used classroom discourse practices to establish engineering } \\
\text { problem criteria and constraints; participated in peer- } \\
\text { evaluated design critiques; elucidated pedagogical choices } \\
\text { made by instructors; reflected on experiences as participant } \\
\text { learners; scaffolded and differentiated engineering activities } \\
\text { for participants who taught in different grade bands }\end{array}$ \\
\hline
\end{tabular}

Although there are multiple models of the engineering design process, in this project we used a three-phase engineering design process (Figure 1). We used this three-phase process for several reasons. First, this three-phase process is used by the engineering college in which the study took place and is the major university attended by high school graduates in the state. Second, this three-phase process closely mirrors the performance expectations outlined in the NGSS, which calls on students to define a problem by specifying criteria and constraints, designing viable solutions to a problem by breaking it down into smaller, more manageable parts, and evaluating the solution based on prioritized criteria and trade-offs (NGSS Lead States, 2013). During the institute, we stressed to our teacher participants the importance of using the three phases iteratively rather than sequentially as needed to design a viable solution to the design problem. In this way, we attempted to avoid hierarchical, linear approaches to design problems. Our corollary was what we often observe in science classrooms - when teachers force students to use the "scientific method" even when an experimental research design is inappropriate for investigating the question or natural phenomenon of focus. Similar to science, we wanted teachers to use science and engineering practices flexibly as needed to address the problem posed. 
Figure 1. Three-phase engineering design process used as the framework for K12 teachers' professional learning.

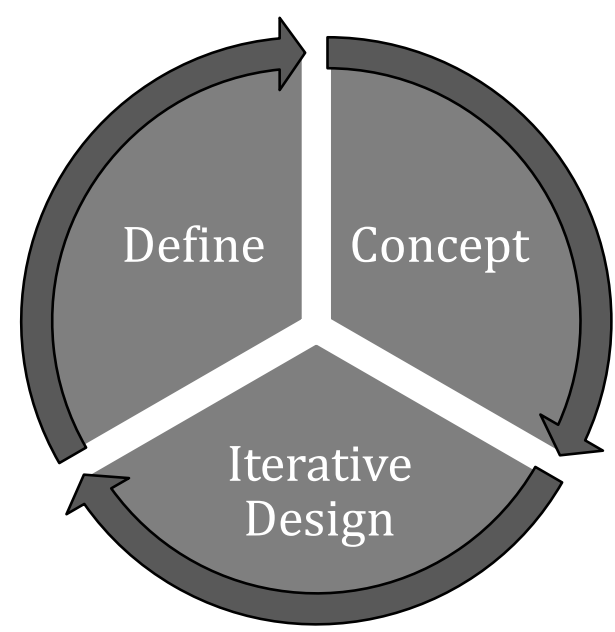

DEFINE. Define end-user criteria. Set constraints based on those criteria.

CONCEPT. Benchmark the design, generate unique and viable concepts. Use systematic, rational process for choosing a concept for prototyping.

ITERATIVE DESIGN. Create prototype of design, document iterations during the process. Conduct fair tests to determine if design meets constraints.

For each of the three design challenges, teachers were prompted to ask questions about the design challenges, define the constraints through consensus, engage in benchmarking research to identify related designs already on the market and evaluate how aspects of established designs could be used to meet the design problem at hand (Bogan and English, 1994; Fridley, Jorgensen, and Lamancusa, 1997). They also used convergent and divergent thinking to generate unique and viable design concepts (drawing on what they learned from benchmarking), complete a tradeoff matrix to determine which design concept was most viable, and use common construction tools to build a prototype that could be tested against design constraints. During prototype construction, teachers were expected to document their iterations to the design and the data they gathered to make decisions about how/when to modify the design. To support teachers' engineering design skills, we facilitated mini-lessons on engineering drawing (sketching + measurement) and using manual and power tools. As necessary, we provided activities related to science content needed to develop viable design concepts. For instance, during the hacked design challenge, we provided teachers with a mini-lesson on electricity, using the pressure and flow of water through a constricted and unconstricted pipe as analogies of voltage, current and resistance in an electrical circuit. At the end of each design challenge, we engaged the teachers in critical reflection about their experiences. During this time, we also unpacked our pedagogical choices as facilitators so as to make clear how we intended to support their learning about engineering design and clarify the pedagogical strategies that could be used in K-12 classrooms.

During the three years of implementation, we made small changes to the activities in the professional learning institute while keeping the goals in place. For instance, during year 2, changed the third design challenge to incorporate design principles because we noticed in year 1 that teachers had difficulty identifying and choosing a design problem around which to formulate instruction for their students. And in year 3, we differentiated the hacked engineering design challenges to ensure the design problems were relevant to the particular teachers in each grade band. The majority of teacher participants were elementary educators who reported teaching more than two of the core content areas. Additional participant demographics are in Table 2. 
Table 2. Participant teachers' grade band and content area teaching assignments.

\begin{tabular}{lccclllll}
$\begin{array}{l}\text { Grade } \\
\text { band }\end{array}$ & Y1 & Y2 & Y3 & & Teaching Assignment & Y1 & Y2 & Y3 \\
\hline K-2 & 2 & 4 & 14 & & Generalist ${ }^{2}$ (mostly K-5) & 6 & 15 & 27 \\
$3-5$ & 5 & 11 & 13 & Mathematics & 1 & -- & 6 \\
$6-8$ & 6 & 9 & 7 & 6 & 7 & 7 \\
$9-12$ & -- & -- & 3 & & Science & Computer science & - & 1 \\
Total $^{1}$ & 13 & 22 & 36 & & Engineering & -- & 2 & 2 \\
\hline
\end{tabular}

${ }^{1}$ Total participants reflect the actual number of teachers who attended the institute. Several teachers indicated their grade level assignment in more than one grade band (e.g., grades 1-5); thus, the sum of the grade bands may equal more than the total participants.

${ }^{2}$ Responsible for teaching more than two core content areas

\section{Data sources}

Pre- and post-institute survey. Each participant was expected to respond to a survey on the first and last days of the professional learning institute. The pre- and post-survey consisted of the same open-ended prompts, which were designed to elicit teachers' understanding of engineering design and the work of engineers. Survey prompts included:

1. What do engineers do?

2. In what ways do you think engineering practices are similar to or different from science practices?

3. To what extent do you think it is possible to enact engineering practices in the grade(s) you teach?

4. What are some of the difficulties you envision with enacting engineering practices in your classroom?

5. How are some of the instructional practices you currently use similar to and/or different from those you might need to enact engineering design in your classroom?

Engineering design process documents. Teacher teams produced a variety of documents as they completed each design challenge; these included tradeoff matrices, sketches of prototypes during brainstorming sessions, benchmarking research, convergent design generation (i.e., final design drawings), and design critique presentations, which generally took the form of one or two PowerPoint slides.

Daily reflective briefs. During the professional learning institute, every teacher participant completed a reflective brief at the end of each day to capture their learning, questions, and concerns. Reflective prompts included:

1. Explain the most important things you took away from today's session.

2. What do you still have questions or feel uncertain about?

3. What additional supports could you use in this PD and/or explain how the facilitators could improve the PD experience?

4. Based on what you've learned so far, describe what aspects you will be able to implement in your classroom.

Engineering design lesson plans. Teacher participants worked in small grade-level or grade-band teams to generate lesson plans that addressed one of the problem statements they had produced during the institute. These lesson plans included alignment to grade level content standards, a narrative that outlined how teachers would implement the engineering design challenge in their classrooms and included student handouts. Teacher teams were challenged to 
produce a working prototype that addressed their design challenge that would serve as an exemplar for students.

Reflections on teaching. We followed up with teachers six months after the professional learning institute to find out how they had enacted engineering design in their classrooms. Teachers included written reflections, student documents and photographs of student designs in their responses.

\section{Data analysis}

Data analysis involved content analysis of pre- and post-institute surveys, engineering design process documents, daily reflective briefs, lesson plans, and follow-up reflections on teaching. We subjected the data to qualitative content analysis following Shreier (2012) using a priori categories based on Reimer et al.'s (2015) five standards of professional learning (see Table 3). Data segments were divided into examples and non-examples of teacher participants' proficiency of the five standards: engineering content and practices, pedagogical content knowledge for teaching engineering, engineering as a context for teaching and learning, curriculum and assessment, alignment to research, standards, and educational practice.

\section{Results}

Research Question 1. To what extent did K12 teachers' knowledge of engineering design change during their participation in professional learning?

Many teachers began with only a superficial understanding of engineering before participating in the professional learning institute. This is not surprising given the recent adoption of NGSS in the state and the fact that engineering had, in the past, been given only cursory inclusion in K12 curricula. At the onset of the institute, teachers illustrated a simplistic understanding of the similarities and differences between engineering and other STEM fields. Teachers' responses to pre-surveys and reflection prompts early in the institute indicate that they held underdeveloped or naïve conceptions of engineering design. As illustrated by the data segments in Table 4, teachers often simply conflated the processes of scientific inquiry and engineering design, or they held the belief that the scientific method was the basis for engineering design and/or a more rigorous or objective process than engineering design.

At the end of the institute, teachers more clearly and precisely indicated how engineering differed from other fields of study, especially science (see Table 4). As indicated by the data segments above, teacher participants were more accurately able to articulate the difference between scientific inquiry and engineering design; namely, that engineering design is used to generate technological solutions to real world problems whereas scientific inquiry is used to better understand the natural world. Moreover, at the end of the professional learning teachers were able to articulate the core practices of engineering design, including identifying end-user criteria and constraints, ideating potential design solutions, building a prototype and testing it based on the design constraints. Evidence of teachers' knowledge of core engineering practices can be found in Table 5. These data are especially important as teachers are expected to engage students in the same practices in NGSS-aligned instruction. Being able to articulate how and when to use particular process skills is important to building teachers' pedagogical content knowledge for engineering (Hynes, 2012; Viiri, 2003). 
Table 3. Alignment of our professional learning model to Reimer et al.'s (2015) standards for teachers of engineering.

Standard

Description of standard

Professional learning for

A. Engineering content and practices teachers should address the fundamental nature, content, and practices of engineering and promote literacy of engineering design.

B. Pedagogical content knowledge for teaching engineering

Professional learning for teachers should emphasize engineering pedagogical content knowledge.

Professional learning for

C. Engineering as a context for teaching and learning teachers should make clear how engineering design and problem solving offer a context for teaching standards of learning in science, mathematics, language arts, reading, and other subjects.

D. Curriculum and assessment

Professional learning for teachers should empower teachers to identify appropriate curricula, instructional materials, and assessment methods.

E. Alignment to research, standards, educational practices

\section{How the professional learning institute addressed the standard}

In the first and second design challenges, teachers were given a problem to address. They worked in small collaborative teams and use engineering design principles to generate a design solution, which was subjected to peer critique and feedback. Teachers used tools to build a working prototype. They were required to test their design, identify weaknesses, and determine how to address those weaknesses. The institute did not address explicitly engineering careers or the interaction of society with the development and use of technological solutions.

Facilitators modeled pedagogical practices for supporting learning in engineering design. These practices included the use of: discourse moves that prompted teachers' reasoning and justification for design choices, individual teacher assignment to teams based on their backgrounds and expertise, scaffolding design challenges to meet the particular needs of teachers in each grade band, using instructional aides to support documentation of process and product during design challenges. After each design challenge, facilitators engaged teachers in deep, critical reflections about pedagogical practices.

Each of the three design challenges required teachers to use science, math, and literacy content knowledge. After each design challenge, teachers were required to identify the content standards used in the challenge and describe how those standards were used.

In the third design challenge, teachers were tasked with identifying content standards for the grade levels they taught and formulate engineering design problems aligned to those standards and geared towards students' interests.

In the second design challenge, teachers were given a pre-existing engineering design curriculum to "hack." Hacking involved modifying the design problem to more closely align with content standards and enhance the curriculum to more explicitly engage students in learning discipline-specific content. Once teachers formulated a design problem for their students (third design challenge), teachers worked in small teams to develop instructional materials and assessment tools such as rubrics for evaluating student performance.

The professional learning institute was developed and implemented by engineering faculty (content experts) and education faculty (educational research and practice experts). As such, the institute employed practices aligned with adult learning theory while emphasizing the job-embedded nature of professional learning so as to maximize the explicit connections between the institute's activities and teacher participants' classroom practice. 
Table 4. Teacher participants' ideas about engineering design before and after participating in the professional learning institute.

Before participating
"They are very similar in the process that
they follow. Scientific practices may not
always solve relevant problems, though."
(27DALU, pre-survey, Y3)1
"I think they're similar because they both
have certain steps to follow such as
determining the problem, testing a solution
and analyzing results." (26anbr, pre-survey,
Y3)

"Scientists use engineering skills to design their projects and experiments." (13octo, presurvey, Y2)

[Engineering and science] "both involve beginning with a question, testing practices, and coming up with a solution. Science has more of a designated process where engineering does not." (10anoc, pre-survey, Y2)

"Both are creative endeavors." (12masp, presurvey, Y3)

"Engineers follow a slightly different procedure and produce a product."

(18ANBA, pre-survey, Y3)

"They are similar in that they both use the scientific method of hypothesis, testing and results." (22ANWIL, pre-survey, Y3)

"Both use the scientific method." (28ANCH, pre-survey, Y3)

"They use the scientific process to solve problems." (7mawi, pre-survey, Y3)
"The engineering design process is similar to science investigations in that both processes involve defining a question, researching possible or current solutions, and then conducting a series of tests. Both practices involve critiques and peer reviews, and various types of presentations. Both use math and science and require precision. Engineering solves a problem or challenge, whereas science answers a question. Science usually requires engineering a way to find the answer." (12 masp, post-survey, Y3)

"Engineering practices are similar to scientific practices in that they tie together. However, engineers develop real applications to given problems instead of scientific principles in which they aren't necessarily looking at a specific problem." (16CEDO, post-survey, Y3)

[Engineering and science] "are similar because they both use an iterative process that is based on constraints and refinement. However, engineering is creating something that will be impactful in some way; whereas, scientific practices are used to discover or prove something." (20anbl, post-survey, Y3)

"Engineering practices go along with the following science practices: ask questions and define problems, develop models, plan and carry out investigations, analyze data, use math, design solutions, engage in arguments from evidence, and communicate information. As the students work through the EDP they are using the science practices. Depending on the grade level, they may or may not use them as in depth, but they are touching on most of them in the process." (20ando, post-survey, Y2)

[Engineering and science] "are similar but engineering practices are inquiry based and develop from real life problems. They identify a problem, create a plan how to solve the problem, devise constraints to test the problem, create a prototype to solve problem, analyze test results and redesign to improve prototype." (31LEWI, post-survey, Y2)

\footnotetext{
${ }^{1}$ For each data segment a code is assigned to each for audit purposes. In the code, the first two numbers and four letters are identifiers assigned to participants to preserve anonymity. The second part of the code refers to the source of the data (pre-survey, post-survey, daily reflections (DR1, DR2, DR3, etc.). The third part of the code refers to the year (Y1, Y2, or Y3) in which the participant attended the institute.
} 
Table 5. Teacher participants' reflections on engineering design processes as evidence of their emerging knowledge of engineering design during the professional learning institute.

\section{Design \\ Process Data from teachers' reflections \\ "I learned how to begin the design process by defining the problem, brainstorming and narrowing ideas down." (02elwi, DR1) \\ "Starting with the design challenge, breaking that down, through question \\ Define generation, to design criteria and constraints." (12masp, DR1) \\ "The steps we modeled to have students brainstorm questions, put on post it notes, and transfer to the matrix." (13BeCh, DR1)}

"Encourage students to iterate designs and learn from one another." (10ANWI, DR3)

"I took away the process of designing a prototype. I was excited to explore materials, be imaginative with sketches even if they were unrealistic, and then choose a sketch to prototype tomorrow. I'm glad that I got to do this myself before I

Concept have my students do it." (28ANCH, DR1)

"The steps of the design process, identifying the constraints, narrowing down the best design." (unknown, DR1)

"Being able to hack a lesson, model \& design it, \& build a prototype to take back with us.” (06imla, DR4)

\section{"Prototyping requires basic tool handling skills that one should not be afraid of."} (12evph, DR2)

"Working with a team requires communication skills and patience, you have tone able to clearly and effectively communicate your needs and understand theirs to complete the task successfully." (12evph, DR3)

Iterative "The most important thing I learned is that it is okay to fail. I am not used to failing,

Design but with the prosthetic that was an epic fail. It is definitely okay." (16CEDO, DR3) "Today's alarm project allowed me to use materials that my students would use to create a functional alarm system. I had to think about the pathways of electricity and figure out how to create a parallel circuit with 3 pathways. I also had to figure out why one of my devices wouldn't work, so I had to go back and continue to test until they all worked." (16MANE, DR4)

Research Question 2. To what extent were teachers able to create and/or adapt engineering design problems aligned with the Next Generation Science Standards and Common Core State Standards for Mathematics?

During the professional learning institute, the facilitators modeled how to use the NGSS and CCSS standards to design engineering design problems that were relevant to students. After modeling this process, teachers were given time to work with grade level and grade band teams to devise their own engineering design problems that could be used in their classrooms. Examples of teacher-generated engineering design problems are shown in Table 6. 
Table 6. Teacher-generated engineering design problems with articulation to NGSS and CCSS standards.

\begin{tabular}{|c|c|c|}
\hline $\begin{array}{l}\text { Grade } \\
\text { Band }\end{array}$ & Problem Statement & $\begin{array}{l}\text { NGSS and CCSS Content } \\
\text { Standards }\end{array}$ \\
\hline $\mathrm{K}-2$ & $\begin{array}{l}\text { Create a safe way for Little Red Riding Hood to cross } \\
\text { through the woods to get to Grandmother's house. }\end{array}$ & $\begin{array}{l}\text { RLK.1-3, RLK.5, RLK.7, SLK.1-2, } \\
\text { SLK.4-6, K-2-ETS1-1, K-2-ETS1-2 }\end{array}$ \\
\hline K-2 & $\begin{array}{l}\text { The three pigs were having trouble building a house to } \\
\text { withstand the force of the wolf's breath. Design a house } \\
\text { that cannot be blown by the Big Bad Wolf. }\end{array}$ & $\begin{array}{l}\text { CCSS.ELA-Literacy.SL.1.1 } \\
\text { (A,B,C), K-2-ETS1-1, K-2-ETS1-2, } \\
\text { CCSS.MATH.CONTENT.1.A.2 }\end{array}$ \\
\hline $3-5$ & $\begin{array}{l}\text { Design a lunch box that keeps food fresh and is theft } \\
\text { proof. }\end{array}$ & $\begin{array}{l}\text { CCSS.5, MD.C.3-Volume, CCSS.5, } \\
\text { MD.C.5, 3-5-ETS1-1, ETS1-2 }\end{array}$ \\
\hline $3-5$ & $\begin{array}{l}\text { Design a system for the classroom that alerts a deaf } \\
\text { student that there is a fire alarm or intruder alert sound. }\end{array}$ & $\begin{array}{l}\text { 4-PS3-3, 4-PS4-1, 3-5-ETS1-1, } \\
\text { ETS1-2, CCSS W.4.7, W.4.8 }\end{array}$ \\
\hline $6-8$ & $\begin{array}{l}\text { It is your birthday! You want to bring a treat to share } \\
\text { with your friend. Design a container that minimizes } \\
\text { energy transfer (melting) of the popsicles from the time } \\
\text { you leave home until you get to school. }\end{array}$ & $\begin{array}{l}\text { MS-PS3-3, MS-ETS1-1, MS-ETS1- } \\
\text { 2, MS-ETS1-3, MS-ETS1-4 }\end{array}$ \\
\hline $6-8$ & $\begin{array}{l}\text { Design and construct a model of an animal heart to } \\
\text { pump blood efficiently and effectively. }\end{array}$ & $\begin{array}{l}\text { MS-LS1-3; MS-ETS1-1, MS- } \\
\text { ETS1-2, MS-ETS1-3; RI.6.8; Math- } \\
\text { 6.E.E.C.9 }\end{array}$ \\
\hline $9-12$ & $\begin{array}{l}\text { Devise a low cost, low tech solution of natural disaster } \\
\text { detection for communities and areas without } \\
\text { technology access. }\end{array}$ & $\begin{array}{l}\text { HS-PS3-3, HS-ETS1-1, HS-ETS1- } \\
\text { 2, HS-ETS1-3; HSN-Q.A.1, HSN- } \\
\text { Q.A.3 }\end{array}$ \\
\hline $9-12$ & $\begin{array}{l}\text { Design a cost-effective device to use solar energy to } \\
\text { create a functional oven. }\end{array}$ & $\begin{array}{l}\text { HS-PS3-3, HS-ETS1-1, HS-ETS1- } \\
2 \text {, HS-ETS1-3 }\end{array}$ \\
\hline
\end{tabular}

In addition to the problem statements that teachers generated with their colleagues, teachers also reported aspects of the institute that they found important with regard to curriculum, instruction, and assessment. In particular, teacher appreciated having time to decode the NGSS and CCSS standards and apply them to engineering design problem statements and curricula. We are somewhat surprised by this finding since the CCSS standards were adopted in 2012 and the NGSS were adopted in 2014 by the department of education in the state in which this study took place.

"I took away from today's session a broader look at the CCSS and the NGSS where I haven't really needed to look before at them." (05joci, DR1, Y3)

"My most important takeaways were deciphering the links the NGSS standards to the engineering process and working with a peer to develop and assess our designs. I rarely get to do development with peers, so this was very worthwhile" (12evph, DR1, Y3).

"I appreciated having the time to take a closer look at the grade level standards, so I can have a better understanding of the different parts (performance standards, crosscutting standards, earth science, physical science, life science, engineering and technology). (27anwi, DR1, Y2)

Teachers highlighted the importance of relevance with regard to the problem statements they generated for students. This is not a surprising finding in that we emphasized relevance as part of the formulation of problem statement for students. However, teachers intimated the idea of relevance beyond typical approaches that emphasize readiness for STEM education in later grades as indicated by the NGSS and CCSS. Instead, teachers related the idea of relevance to the 
social and individual dimensions of learning (Stuckey, et al., 2013). The data segments below provide evidence about teachers' views of relevance:

"It is important to make each lesson 'your own.' Be sure the lessons are meaningful, impactful, aligned to school's standards, and feasible for your classroom. I liked going through the hacking process since we all share ideas and adapt to our needs" (10ANWI, DR4).

"Knowledge of the steps in the design process as well as the criteria for choosing an appropriate problem based on standards and relevancy to students" (10ANWI, DR1).

"I was able to create a cross curricular lesson using Earth science standards and make it extremely relatable to my students. It was a huge help having middle school science teachers present to converse with. I would not have been able to pinpoint the Earth science standards necessary for my "hack" as quickly. We even discovered that the lesson that I developed would fit in to what they developed for their classrooms" (unknown, DR4).

"Make sure the design problems are relevant to your students, give students enough time to think and respond" (10maco, DR1).

Research Question 3. To what extent were teachers' confidence and skills for enacting engineering design in their classrooms influenced by their participation in professional learning?

At the end of the institute, teachers were able to articulate how they would leverage engineering design principles and pedagogies to support students' learning. Perhaps most importantly, teachers discussed how engineering design could be integrated into the curriculum rather than added onto the existing curriculum. We assert that integration is a critical for engineering design to become a foundational part of the K-12 curriculum. In contemporary K-12 classrooms, were instruction is already overburdened by standards, testing, and rigorous scope and sequences for subject area curricula, adding yet another expectation for teaching is impossible. Several teachers noted the cross-curricular connections to engineering design. For instance, one teacher noted: "I can see many overlaps with the way I teach. I think even the projects for novel studies are similar to the engineering design process. I was even thinking I will adopt terms like high precision, low precision in addition to criteria and constraints in much of what I do. This will definitely ensure that my students are comfortable with engineering design process" (12masp, DR4, Y3). An upper elementary teacher indicated that she was connecting her work from the institute to a unit on space science, which was part of the regular of the grade level science curriculum: "I have the criteria and constraints template. I love this for so many projects! I will be using this in greater detail, as well as the other design planning templates later in the year. I have a giant floor map of Mars and was given four Thames \& Kosmos remote-control space explorer machine kits. My students will work in teams to design, build, calibrate and test Mars rovers on the floor map" (JD, RT1, Y3).

Another teacher indicated her confidence with the engineering design process, which allowed her to be more open to potential synergies across the early elementary curriculum: "This fall we did the EIE Catching the Wind: Designing Windmills kit for the first time and we used it with the whole class, not just the "advanced" students. At first, I wasn't a fan of the kit, 
since there was a long story with a lot of complex vocabulary in it. However, I did end up appreciating the kit/liking it. It did teach the class the Engineering Design Process and then they used that to create a wind mill blade and sail mast.

Since they are familiar with engineering design now, it's easier to do design challenges in class. To go along with our social studies unit about colonial life, last week the students designed a pilgrim house. They had certain criteria and constraints and it went well. They had cut out people that had to fit in the house, the house needed a roof and walls. Also, the house needed to keep the people safe from the elements. From these three activities, the class knows that it's okay (and expected) if their design doesn't work well the first time. They then try to improve it and retest it." (KT, RT1, Y3)

Noticing the synergies among subjects in the curriculum allowed teachers to more readily leverage engineering design beyond that which was expected by their district: "The engineering design process is something that I just used in the EIE kit and that was it. I really didn't have students develop their own problems and have challenges except for a project towards the end of the year. However, I can start trying to do this during math and have students learn by experimenting and different design challenges. I can foresee many teachable moments" (16CEDO, post-survey, Y3). And this teacher indicated how their new knowledge would lead to more authentic connections for students in learning activities: "In my room, students always reflect on their learning and they are familiar with documenting their work. Identifying and using the engineering design process will refine and frame their work. I intend to make their challenges more authentic and to focus on my EDP vocabulary in the process" (03ELOT, DR4, Y2).

Finally, one $5^{\text {th }}$ grade teacher indicated that her engineering design problem, with accompanying lessons, was highly engaging for her students and rewarding for her to teach in her STEM enrichment class: "The fifth-grade students are using engineering practices to design and build tiny house prototypes.... They collaborated and brainstormed criteria and constraints and sketched their tiny house designs. The students used the trade-off matrix to decide on their design. Each student team just finished sharing during their first critique! They have also been doing reflections each session in their EDP notebook." (TL, RT1, Y3). Figure 2 shows students collaborating on their designs.
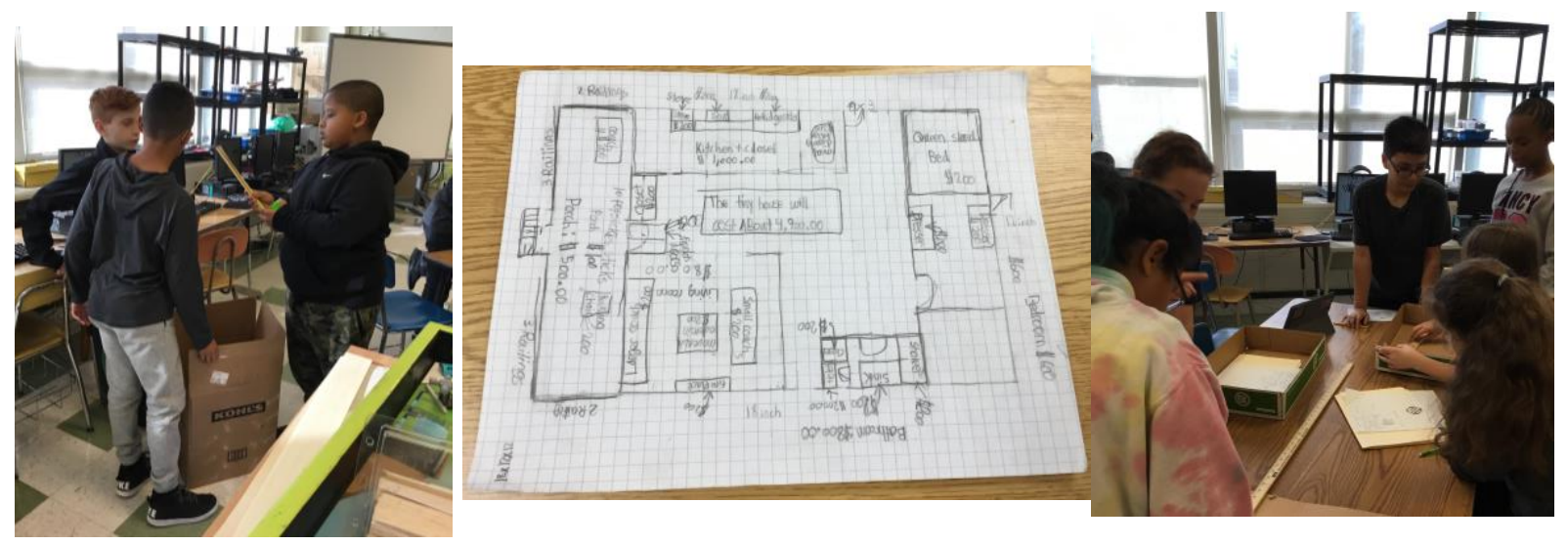

Figure 2. Students engaged in the design and construction of prototypes. 


\section{Discussion and Implications}

Adoption of NGSS presents an opportunity for the engineering profession to expand and diversify its talent pipeline; however, this opportunity will only be realized if K12 teachers are well-prepared to deliver high quality, grade-band appropriate engineering experiences in their own classrooms. Our professional learning institute, aligned with research on teacher education for engineering design, was intended to enhance teachers content knowledge and pedagogical skills for engineering design in K12 classrooms. Similar to Donna (2012) and Cunningham and Carlsen (2014), data from our study indicates that the following foci are effective drivers of teacher learning: (1) developing basic knowledge of engineering design processes, (2) engaging in engineering design challenges with grade level or grade band colleagues, (3) reflecting on the design challenge experience as learners and as teaches, (4) exploring connections among engineering design and content standards, (5) planning for enactment in classrooms.

Our goal was to support K-12 educators as engineering teachers and as engineers of the curriculum. As stated by Cunningham and Carlsen (2014):

As teachers engineer, they construct more than a technology - they also build their personal understanding of the engineering practices that together constitute design. Meanwhile, workshop or course facilitators ask participants to reflect upon the engineering practices that they are utilizing. Teachers may wish to consider how their students might react to an engineering experience — what will be new for students and where might students need scaffolding or support? (p. 204)

The professional learning activities created for our institute may be used as a model to empower teachers to develop and adapt standards-aligned curriculum to incorporate engineering design. This is especially important in the era of STEM integration, where instructional models vary widely. Ostensibly, the four foundational fields of STEM - science, technology, engineering and mathematics - interact and overlap in the real world, both in professional settings and in personal ones. It is only within formal education that these four foundational domains become silo-ed, where students learn about only life science or only computer science or only engineering in courses designed ostensibly for those purposes. Moreover, teachers are generally credentialed in one of these silos rather than more than one or an integration of more than one of these fields. Often what results from this educational model are teachers and students who are unable to communicate and work adeptly across the domains.

The disconnect between the contemporary realities of schooling and the modern workforce is exacerbated because students' knowledge and skills are compartmentalized within STEM domains in K-12 education. As such, their ability to transfer those knowledge and skills facilely among STEM domains becomes truncated, especially as they traverse from elementary through middle grades and secondary education, where courses become more and more specialized. Evidence abounds regarding this limitation in K12 schooling - students' inability to transfer their knowledge of slope in their algebra class to correlational relationships among variables in their science class or their inability to use programming logic in their computer science class to develop a predictive model in their math class. If flexible appropriation and transfer of knowledge and skills of connected STEM knowledge is the goal for students in the $21^{\text {st }}$ century, then our models for teacher preparation and ongoing professional learning should follow suit. 


\section{References}

Bogan, C.E., \& English, M.J. (1994), Benchmarking for best practices: Winning through innovative adaptation, vol. 1. New York, NY: McGraw-Hill.

Brophy, S. B., Klein, S. S., Portsmore, M., \& Rogers, S. (2008). Advancing engineering education in P-12 classrooms. Journal of Engineering Education, 97(3), 369-387.

Cunningham, C. M., \& Carlsen, W. S. (2014), Teaching engineering practices. Journal of Science Teacher Education, 25(2), 197-210.

Custer, R. L., \& Daugherty, J. L. (2009). Professional development for teachers of engineering: Research and related activities. The Bridge, 39(3), 18-24.

Daugherty, J. L., \& Custer, R. L. (2012). Secondary level engineering professional development: Content, pedagogy, and challenges. International Journal of Technology and Design Eduation, 22, 51-64.

Donna, J. D. (2012). A model for professional development to promote engineering design as an integrative pedagogy within STEM education. Journal of Pre-college Engineering Education Research, 2(2), 1-8.

Duncan, D., Diefes-Dux, H., \& Gentry, M. (2011). Professional development through engineering academies: An examination of elementary teachers' recognition and understanding of engineering, Journal of Engineering Education, 100(3), 520-539.

English, L. D., Hudson, P., \& Dawes, L. (2013). Engineering-based problem solving in the middle school: Design and construction with simple machines. Journal of Pre-College Engineering Education Research, 3(2), 5.

Fridley, J. L., Jorgensen, J. E., \& Lamancusa, J. S. (1997). Benchmarking: A process basis for teaching design. Paper presented at the Frontiers in Education Conference, Pittsburgh, PA, paper number 1031.

Guzey, S. S., Tank, K., Wang, H.-H., Roehrig, G., \& Moore, T. J. (2014). A high-quality professional development for teachers of grades 3-6 for implementing engineering into classrooms. School of Engineering Education Faculty Publications. Paper 4. http://dx.doi.org/10.1111/ssm.12061

Hsu, M.-C., Purzer, S., \& Cardella, M. E. (2011). Elementary teachers' views about teaching design, engineering, and technology. Journal of Pre-College Engineering Education Research, 1(2), 31-39.

Hynes, M. M. (2012). Middle school teachers' understanding and teaching of the engineering design process: A look at subject matter and pedagogical content knowledge. International Journal of Design Education, 22, 345-360.

Moore, T. J., Glancy, A. W., Tank, K. M., Kersten, J. A., Smith, K. A., \& Stohlmann, M. S. (2014). A framework for quality K-12 engineering education: Research and development. Journal of Pre-College Engineering Education Research, 4(1), 2.

National Research Council. (2012). A framework for K-12 science education: Practices, crosscutting concepts, and core ideas. Washington, DC: National Academies Press.

NGSS Lead States. (2013). Next generation science standards: For states, by states. Washington, DC: National Academies Press.

Penuel, W. R., Fishman, B. J., Yamaguchi, R., \& Gallagher, L. P. (2007). What makes professional development effective? Strategies that foster curriculum implementation. American Educational Research Journal, 44(4), 921-958.

Pinnell, M., Rowley, J., Preiss, S., Blust, R. P., Beach, R., \& Franco, S. (2013). Bridging the gap 
between engineering design and PK-12 curriculum development through the use the STEM education quality framework. Mechanical and Aerospace Engineering Faculty Publications. 193. http://ecommons.udayton.edu/mee_fac_pub/193

Reimers, J. E., Farmer, C. L., \& Klein-Gardner, S. S. (2015). An introduction to the standards for preparation and professional development for teachers of engineering. Journal of Precollege Engineering Education Research, 5(1), 40-60.

Rogers, M. P., Abell, S., \& Lannin, J. (2007). Effective professional development in science and mathematics education: Teachers' and facilitators' views. International Journal of Science \& Mathematics Education, 5(3), 507-532.

Schreier, M. (2012). Qualitative content analysis in practice. Los Angeles: Sage.

Stuckey, M., Hofstein, A., Mamlok-Naaman, R., Eilks, I. (2013). The meaning of 'relevance' in science education and its implications for the science curriculum. Studies in Science Education, 49(1), 1-34.

Viiri, J. (2003). Engineering teachers' pedagogical content knowledge. European Journal of Engineering Education, 28(3), 353-359.

Zarske, M. S., Sulivan, J. F., Carlson, L. E., \& Yowell, J. L. (2004). Teachers teaching teachers: Linking K-12 engineering curricula with teacher professional development. Research paper presented at the ASEE Annual Conference. 